\title{
LETTER
}

\section{Probiotics in patients with severe acute pancreatitis}

\author{
Wan-Jie Gu and Jing-Chen Liu* \\ See related research by Gou et al., http://ccforum.com/content/18/2/R57
}

Gou and colleagues have conducted a systematic review and meta-analysis of randomized controlled trials to determine the effects of probiotics in the treatment of severe acute pancreatitis [1]. We congratulate and applaud their important work, but several important issues should be noted.

First, in the 'Methods' subsection of the Abstract, the authors stated 'Eligible studies were randomized controlled trials that compared the effects of probiotics administration with placebo treatment in patients with predicted SAP [severe acute pancreatitis]'. However, in Table two, the information for the Control group suggests that most of the eligible studies compared probiotics with control (that is, heat-inactivated L. plantarum 299 per serving, bioactive fibers, or water) rather than placebo. The two parts seem inconsistent.

Second, in the 'Inclusion and exclusion criteria' subsection, the authors stated 'We included all human RCTs [randomized controlled trials] that investigated the effects of probiotics in SAP patients', but the trial of Plaudis and colleagues [2] was just a prospective feasibility study. Whether this study was a randomized controlled trial or not remains unclear, just as acknowledged by the authors in Table one. Strictly speaking, the Plaudis and colleagues trial should not be included.

Third, in the 'Statistical analysis' subsection, the authors stated 'The Mantel-Haenszel random-effects model and fixed-effects model were used for data with and without significant heterogeneity, respectively'. What is the meaning of significant heterogeneity? $\mathrm{I}^{2}>50 \%$ or something else? It is ambiguous and the authors need to clarify.

Lastly, in Figure two, Besselink and colleagues [3] accounts for $69.9 \%$ (pancreatic infection), $81.2 \%$ (total infection), and $84.1 \%$ (mortality) of the total weight. The authors should perform sensitivity analysis by omitting the Besselink and colleagues trial to test the robustness of their results.

\section{Competing interests}

The authors declare that they have no competing interests.

\section{Authors' contributions}

WJG and JCL conceived the study, participated in the design, collected the data, and drafted the manuscript. All authors read and approved the final manuscript.

\section{Published: 03 Jul 2014}

\section{References}

1. Gou S, Yang Z, Liu T, Wu H, Wang C: Use of probiotics in the treatment of severe acute pancreatitis: a systematic review and meta-analysis of randomized controlled trials. Crit Care 2014, 18:R57.

2. Plaudis H, Pupelis G, Zeiza K, Boka V: Early low volume oral synbiotic/ prebiotic supplemented enteral stimulation of the gut in patients with severe acute pancreatitis: a prospective feasibility study. Acta Chir Belg 2012, 112:131-138.

3. Besselink MG, van Santvoort HC, Buskens $E$, Boermeester MA, van Goor $H_{\text {, }}$ Timmerman HM, Nieuwenhuijs VB, Bollen TL, van Ramshorst B, Witteman BJ, Rosman C, Ploeg RJ, Brink MA, Schaapherder AF, Dejong CH, Wahab PJ, van Laarhoven CJ, van der Harst E, van Eijck CH, Cuesta MA, Akkermans LM, Gooszen HG: Probiotic prophylaxis in predicted severe acute pancreatitis: a randomised, double-blind, placebo-controlled trial. Lancet 2008, 371:651-659.

\section{$10.1186 /$ cc13968}

Cite this article as: Gu and Liu: Probiotics in patients with severe acute pancreatitis. Critical Care 2014, 18:446

* Correspondence: jingchenliu1964@sina.cn

Department of Anaesthesiology, the First Affiliated Hospital, Guangxi Medical University, Nanning 530021 Guangxi, China

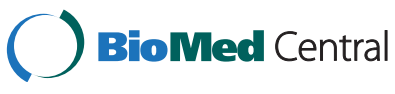

(c) 2014 Gu and Liu; licensee BioMed Central Ltd. This is an Open Access article distributed under the terms of the Creative Commons Attribution License (http://creativecommons.org/licenses/by/4.0), which permits unrestricted use, distribution, and reproduction in any medium, provided the original work is properly credited. The Creative Commons Public Domain Dedication waiver (http://creativecommons.org/publicdomain/zero/1.0/) applies to the data made available in this article, unless otherwise stated. 